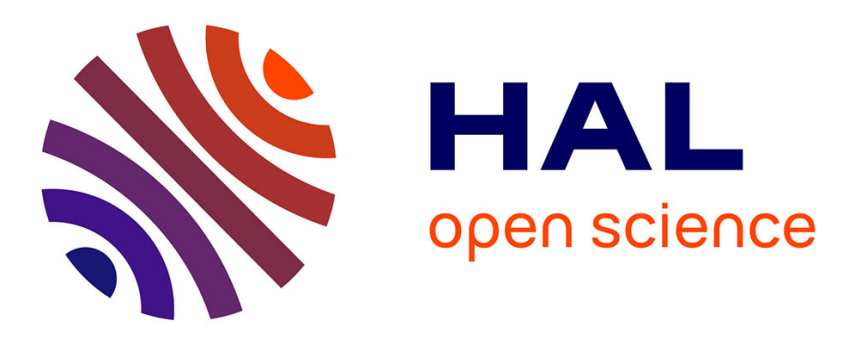

\title{
Formation of cobalt(II), nickel(II) and copper(II) chloro complexes in alcohols and the Irving-Williams order of stabilities
}

\author{
Mustayeen Khan, Gilles Bouet, Frangois Vierling, Jean Meullemeestre, \\ Marie-José Sehwing
}

\section{To cite this version:}

Mustayeen Khan, Gilles Bouet, Frangois Vierling, Jean Meullemeestre, Marie-José Sehwing. Formation of cobalt(II), nickel(II) and copper(II) chloro complexes in alcohols and the Irving-Williams order of stabilities. Transition Metal Chemistry, 1996, 21, pp.231-234. 10.1007/BF00165973 . hal03187764

\section{HAL Id: hal-03187764 \\ https://univ-angers.hal.science/hal-03187764}

Submitted on 8 Apr 2021

HAL is a multi-disciplinary open access archive for the deposit and dissemination of scientific research documents, whether they are published or not. The documents may come from teaching and research institutions in France or abroad, or from public or private research centers.
L'archive ouverte pluridisciplinaire HAL, est destinée au dépôt et à la diffusion de documents scientifiques de niveau recherche, publiés ou non, émanant des établissements d'enseignement et de recherche français ou étrangers, des laboratoires publics ou privés. 


\title{
Formation of cobalt(II), nickel(II) and copper(II) chloro com- plexes in alcohols and the Irving-Williams order of stabilities
}

\author{
Mustayeen Khan* and Gilles Bouet \\ Laboratoire de Chimie de Coordination, Université d'Angers, Faculté de Pharmacie, 16 Boulevard Daviers, F-49100 \\ Angers, France
}

\author{
François Vierling, Jean Meullemeestre and Marie-José Schwing \\ Laboratoire de Chimie Physique, UA CNRS 405, EHICS, 1 Reu Blaise Pascal, F-67000 Strasbourg, France
}

\section{Summary}

$\mathrm{Co}^{\mathrm{II}}$ chloro complexes were studied in $\mathrm{MeOH}$ at $25^{\circ} \mathrm{C}$ and at constant ionic strength of $1 \mathrm{~mol} \mathrm{dm}^{-3}$. Formation of three complexes is postulated for which the overall stability constants are calculated: $\log \beta_{1}=1.2$, $\log \beta_{2}=1.7$ and $\log \beta_{3}=1.4$. The electronic spectra and the formation curves of the identified species are presented for the first time in this medium. The results are compared with those obtained in other alcohols and increasing stability with increasing molecular weight of the solvents is established. Further comparative study showed that the maximum stability of the chloro complexes is found with the $\mathrm{Cu}^{\mathrm{II}}$ ion as the central atom. This confirms the IrvingWilliams order of stabilities for the first transition metal complexes in this alcoholic medium and the result is explained in terms of the second ionization potential of the elements.

\section{Introduction}

We have recently reported the results of chloro complexes of cobalt(II) in ethanol and propan-2-ol ${ }^{(1)}$. Under the experimental conditions, three mononuclear complexes were identified and their stability constants and electronic spectra were calculated. As a detailed bibliography was given in that publication, we shall give here only a brief summary of some earlier results. After a quantitative study in solution, most authors such as Katzin ${ }^{(2)}$, Fine ${ }^{(3)}$ and $\operatorname{Cotton}^{(4)}$ reported the presence of two complexes in solution with tetrahedral groupings, along with the absence of the formation of the tetrachlorocobaltate. Stability constants of the species present were calculated and specific maximum absorption bands were assigned to them. For Wendling and Benali-Baitich ${ }^{(5)}\left[\mathrm{CoCl}_{4}\right]^{2-}$ formed in solution but did not exceed $2.5 \%$, even in concentrated solutions. On the other hand, Zeltman ${ }^{(6)}$ and Bjerrum ${ }^{(7)}$ have reported the presence of four complexes: namely $\mathrm{CoCl}^{+}, \mathrm{CoCl}_{2}, \mathrm{CoCl}_{3}^{-}$and $\mathrm{CoCl}_{4}^{2-}$. We believe that, in solution, highly coordinated complexes are formed exclusively in some dipolar aprotic solvents which may explain why they are absent in most other solvents ${ }^{(8)}$.

This study reports the results of a spectrophotometric investigation of cobalt(II) chloro complexes in methanol, at constant ionic strength of $1 \mathrm{~mol} \mathrm{dm}^{-3}$ and at $25^{\circ} \mathrm{C}$. For the equilibrium:

$$
\mathrm{Co}^{2+}+j \mathrm{Cl}^{-} \rightleftharpoons \mathrm{CoCl}_{j}^{(j-2)-}
$$

the apparent overall stability constants, $\beta_{j}$, were calculated, where $\beta_{j}=\left[\mathrm{CoCl}_{j}^{(j-2)-}\right] /\left(\left[\mathrm{Co}^{2+}\right]\left[\mathrm{Cl}^{-}\right]^{j}\right)$. The

\footnotetext{
* Author to whom all correspondence should be directed.
}

stability, as well as the electronic spectra, of these chloro complexes of cobalt(II) are compared with the results obtained in other alcohols in order to determine the solvent effect, if any. Eventually all these results are in turn compared with those of the nickel(II) and copper(II) chloro complexes in these three alcohols and their stabilities are examined with respect to the central metal ions.

\section{Experimental}

Methanol (p.a., Merck) was used without further treatment. Stock solutions were prepared with $\mathrm{LiCl}, \mathrm{LiClO}_{4}$ and $\mathrm{Co}\left(\mathrm{ClO}_{4}\right)_{2} \cdot 6 \mathrm{H}_{2} \mathrm{O}$ (all Fluka, p.a.), and the preparation of subsequent solutions under investigation was carried out by dilution. The absorption variations were measured with a Beckman UV 5230 spectrophotometer at $25.0 \pm 0.5^{\circ} \mathrm{C}$ and a solution of the supporting electrolyte $\mathrm{LiClO}_{4}, 1 \mathrm{~mol} \mathrm{dm}^{-3}$ was the spectrophotometric reference. The final analytical concentration of the metal was maintained at $5 \times 10^{-3} \mathrm{~mol} \mathrm{dm}^{-3}$; that of the ligand varied from 0.001 to $1.0 \mathrm{~mol} \mathrm{dm}^{-3}$.

Under these experimental conditions the formation of polynuclear complexes was negligible; formation of only the mononuclear complexes is taken into account for all mathematical calculations. These calculations were carried out on an IBM 3090 computer at the Universite Louis Pasteur, Strasbourg.

\section{Results and discussion}

Figure 1 shows the experimental spectra of the methanolic cobalt(II) chloride solutions in the u.v.-vis. region. The free solvated cobalt(II) ion had a minimum at $c a$. $205 \mathrm{~nm}$. The addition of chloride ions produced a peak at $225 \mathrm{~nm}$ which increased in intensity and finally merged with the initial maximum at ligand concentration of $c a$. $0.4 \mathrm{~mol} \mathrm{dm}^{-3}$. This absorption band underwent a significant bathochromic shift until $240 \mathrm{~nm}$, where it became asymmetric for higher ligand concentrations.

In the vis. region a maximum appeared at $680 \mathrm{~nm}$ for low concentrations. This band increased in intensity with increasing chloride ion concentration and showed residual absorption at ca. 600 and $640 \mathrm{~nm}$. It is interesting to note that this spectrum was nearly identical to that of cobalt(II) chloride solutions in dimethyl sulfoxide (DMSO) for chloride ion concentrations up to $0.02 \mathrm{moldm}^{-3(8)}$. This is not surprising because the two solvents have dielectric constants, $\varepsilon_{\mathrm{r}}$, of nearly the same magnitude $(\mathrm{MeOH}=33, \mathrm{DMSO}=45)$.

A mathematical treatment of the experimental absorption, $A$, data permits determination of the minimum number of species present in the solution ${ }^{(9)}$ for which the stability constants are calculated by a laboratory pro- 


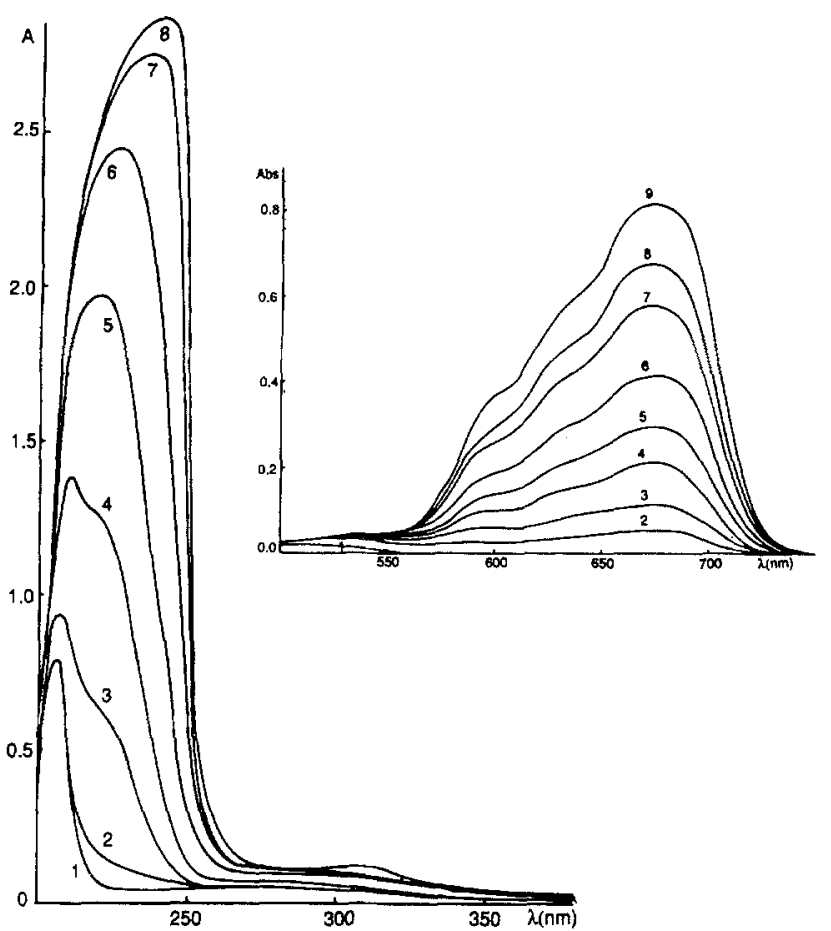

Figure 1. Absorption spectra of $\mathrm{Co}^{\mathrm{II}}$ in $\mathrm{LiCl}-\mathrm{LiClO}_{4}-\mathrm{MeOH}$ mixtures. $\left[\mathrm{Co}^{2+}\right]=5 \times 10^{-3} \mathrm{~mol} \mathrm{dm}^{-3} ; l=1 \mathrm{~cm} \quad(0.5 \mathrm{~cm}$ in U.V. for $\left[\mathrm{Cl}^{-}\right]>0.5 \mathrm{~mol} \mathrm{dm}{ }^{-3}$ U.V. spectra/ $\left[\mathrm{Cl}^{-}\right]: 1 / 0,2 / 0.01$, $3 / 0.08,4 / 0.2,5 / 0.4,6 / 0.6,7 / 0.8,8 / 1.0$. Vis: $1 / 0,2 / 0.3,3 / 0.4,4 / 0.5$, $5 / 0.6,6 / 0.7,7 / 0.8,8 / 0.9,9 / 1.0$.

gram based on a least-squares method. The details of these calculations have been given in one of our earlier publications ${ }^{(10)}$. Nevertheless, we may recall here that for each wavelength, $\lambda$, and $S_{\lambda}$ function of the parameter $\beta_{j}$ and the specific extinction coefficient, $\varepsilon_{j}$, in terms of the free ligand concentration, $c$ is expressed by:

$$
S_{\lambda}=S_{\lambda}\left(\beta_{j}, \varepsilon_{j}, c_{i}\right)=\sum_{i=1}^{N}\left(\frac{A_{i \exp }-A_{i \mathrm{calcd}}}{A_{i \exp }}\right)^{2}
$$

where $A_{\exp }$ and $A_{\text {calcd }}$ are the experimental and theoretically calculated absorptions, respectively, and $N$ is the number of solutions. The corresponding standard deviation, $\sigma_{\lambda}$, describes the agreement between experimental and calculated absorption values at each wavelength. For global harmony between the theoretical and calculated values of the whole set of data, $\sigma$ is expressed in terms of $\sigma_{2}$ and $L$, where $L$ is the number of wavelengths:

$$
\sigma=\left(\frac{\sum_{\lambda=1}^{L} \sigma_{i}^{2}}{L}\right)^{1 / 2}
$$

Of course, the lower the value of $\sigma$, the better is the agreement between the experimental and theoretical values.

Our laboratory program combines a classical leastsquares method analytically expressed by Byé et al..$^{(1)}$ and a Marquardt method ${ }^{(12)}$ which permits one to rapidly reach the minimum of $S_{\lambda}$.

According to this interpretation three complexes are present in the solution for which the calculated formation constants are:

$$
\begin{array}{llll} 
& \mathrm{CoCl}^{+} & \mathrm{CoCl}_{2} & \mathrm{CoCl}_{3}^{-} \\
\beta_{i} & 15 & 52 & 26 \\
\log \beta_{i} & 1.2 & 1.7 & 1.4
\end{array}
$$

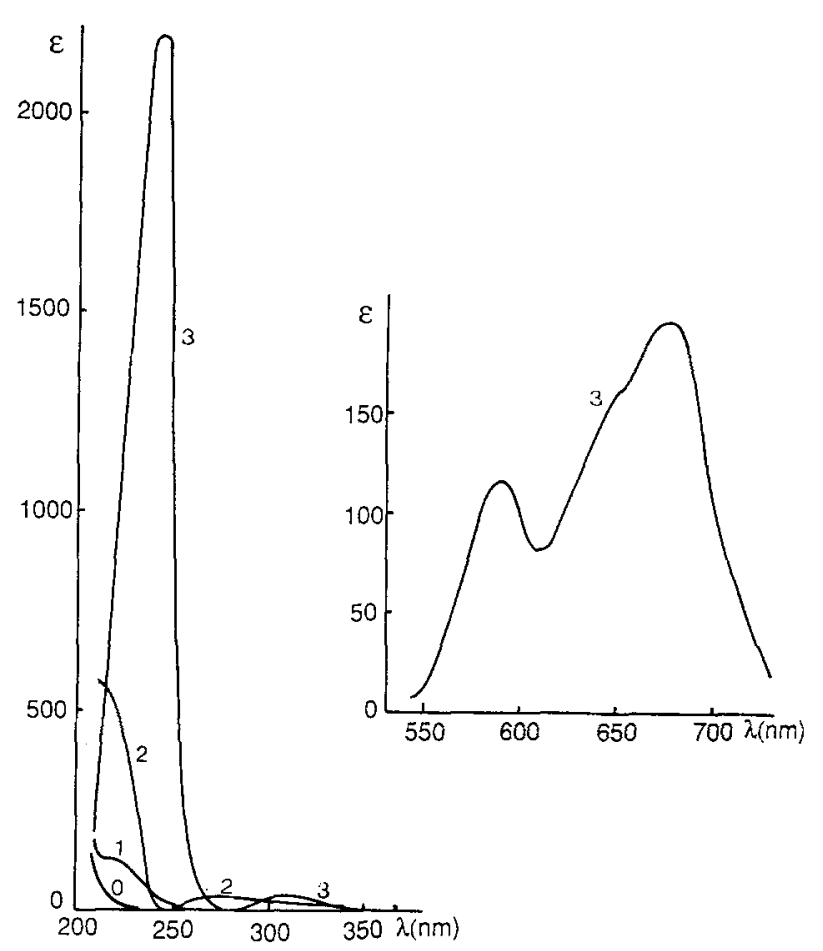

Figure 2. Calculated electronic spectra of $\mathrm{Co}^{\text {II }}$ chloro complexes in $\mathrm{MeOH}$ solutions: $0, \mathrm{Co}^{2+} ; 1, \mathrm{CoCl}^{+} ; 2, \mathrm{CoCl}_{2} ; 3, \mathrm{CoCl}_{3}^{-}$.

Byé et al. showed that, in the case of resolution by the least-squares method, the function to be minimized can be assimilated to a paraboloid of $n$ dimensions. The calculations determine the zone of dispersion of parameters in which the possibility of finding them is $95 \%$, which is the zone of the sum minimum, $S_{\mathrm{m}}$, surrounded by the standard deviation: $S_{\mathrm{m}} \pm 4 \sigma^{2}$. The values of the stability constants are therefore given with an uncertainty of $\mathrm{ca} .12 \%$ : $\beta_{1}=15 \pm 2, \beta_{2}=52 \pm 6, \beta_{3}=36 \pm 3$. The standard deviation $\sigma$ is 0.068 for this set of parameters, which means that the absorptions are recalculated within $7 \%$ of their original values. With the help of these constants the electronic spectra of the three complexes were calculated and are presented in Figure 2.

The monochloro complex has a maximum of low intensity of $220 \mathrm{~nm}$ with a specific extinction coefficient, $\varepsilon$, of $130 \mathrm{dm}^{3} \mathrm{~mol}^{-1} \mathrm{~cm}^{-1}$. The dichloro complex exhibits its peak at $c a .210 \mathrm{~nm}\left(\varepsilon=580 \mathrm{dm}^{3} \mathrm{~mol}^{-1} \mathrm{~cm}^{-1}\right)$ and another peak of very low intensity at $275 \mathrm{~nm}$ $\left(\varepsilon=40 \mathrm{dm}^{3} \mathrm{~mol}^{-1} \mathrm{~cm}^{-1}\right)$. Both these species have no significant absorptions in the vis. region of the spectrum. The trichloro complex, on the contrary, has a band of very high intensity at $240 \mathrm{~nm}\left(\varepsilon=2200 \mathrm{dm}^{3} \mathrm{~mol}^{-1} \mathrm{~cm}^{-1}\right)$ followed by another absorption in the u.v. region centred at $310 \mathrm{~nm}\left(\varepsilon=50 \mathrm{dm}^{3} \mathrm{~mol}^{-1} \mathrm{~cm}^{-1}\right)$. In the vis. region of the spectrum it presents several absorptions as well as shoulder peaks. Two clearly established maxima are located at 590 and $675 \mathrm{~nm}\left(\varepsilon=115\right.$ and $200 \mathrm{dm}^{3} \mathrm{~mol}^{-1} \mathrm{~cm}^{-1}$, respectively); two shoulders are observed at 650 and $710 \mathrm{~nm}$. We note here that this shoulder appears in $\mathrm{PrOH}$ at $660 \mathrm{~nm}$ but is absent in $\mathrm{EtOH}^{(1)}$.

The distribution curves for the simultaneous formation of the different species present in solution are shown in Figure 3. It is noteworthy that the monochloro and dichloro complexes predominate within the experimental limits of ligand concentration.

Table 1 lists the logarithms of the stability constants of the identified chloro complexes of cobalt(II), nickel(II) 


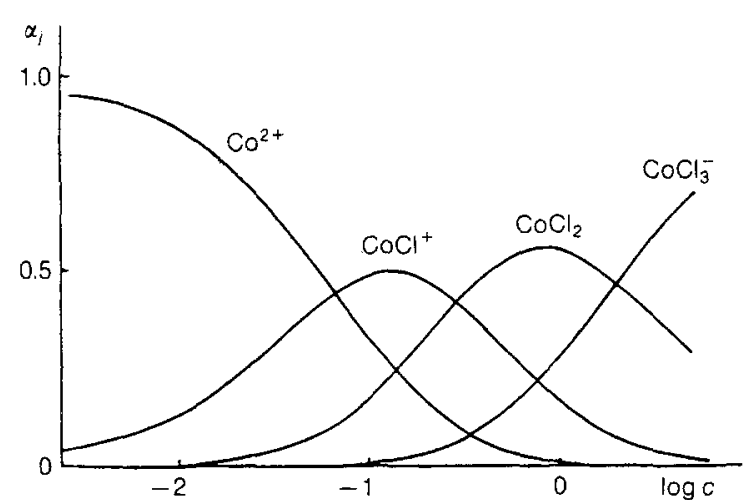

Figure 3. Formation curves of the $\mathrm{Co}^{\mathrm{II}}$ chloro complexes in $\mathrm{MeOH}(\alpha=$ degree of formation; $c=$ free ligand concentration).

and copper(II). We have already reported that the stability of the copper complexes ${ }^{(13)}$ and the nickel complexes ${ }^{(14)}$ depends on the molecular weight of the alcohol: $\log \beta_{j}$ is an increasing linear function of their molecular weight.

Figure 4 shows that the same is true for cobalt(II) chloro complexes. Of course, if this were not so it would be surprising and difficult to explain. This phenomenon, somewhat irregular for cobalt, improves for nickel and is quite uniform when the central ion is copper. A probable explanation for this regularity in case of copper is the high stability of the complexes formed with this metal.

With the reaction of a single ligand (chloride ion) with the three metals ions $\left(\mathrm{Co}^{2+}, \mathrm{Ni}^{2+}, \mathrm{Cu}^{2+}\right)$ in different solvents we can now discuss quantitatively the stability of the complexes formed as a function of the central metal ion. Irving and Williams ${ }^{(18)}$ pointed out that the formation constants of the complexes of the divalent ions of the first transition series increase to a maximum for copper. The authors found the order: $\mathrm{Mn}<\mathrm{Fe}<\mathrm{Co}<$ $\mathrm{Ni}<\mathrm{Cu}>\mathrm{Zn}$ for the stability of complexes, irrespective of the nature of the coordinated ligand. This order, now known as the Irving-Williams series, has been explained by the authors with respect to the reciprocal of the ionic radii and the second ionization potentials of the elements.

There is of course, no single factor which accounts for the stabilities of the complexes. The charge:radius ratio is considered to be of prime importance and that is why, when a metal forms complexes with the same ligand in more than one oxidation state, the species of the higher oxidation state are usually more stable. Other factors influencing stabilities are the decreasing ionic radii and the increasing ionic potentials. However, all these factors are interlinked.

It is difficult to explain this order of stability taking into account solely the ionic radii, $r$, of the metallic ions, especially when there is a certain incongruency in their values in the scientific literature. It is interesting to note that although the values of the second ionization poten-

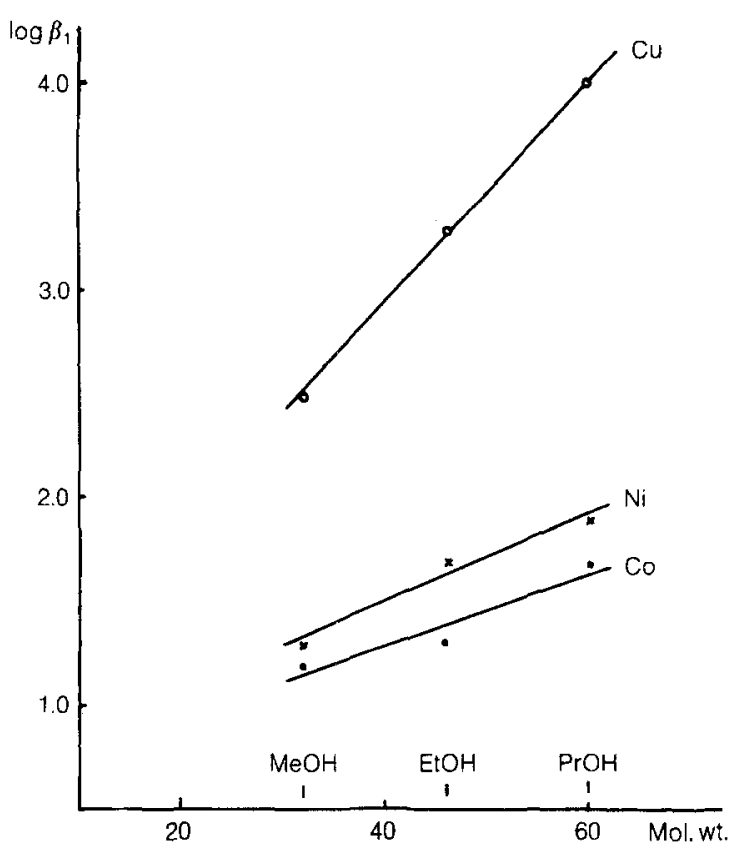

Figure 4. Variation of the logarithm of the stability constants of the monochloro complexes of $\mathrm{Co}^{\mathrm{II}}$ with the mol. wt. of the solvents.

tials of the first transition elements in various documents are the same, different books and treatises give disparate values for their ionic radii. Table 2 lists this divergence.

An examination of Table 2 therefore infirms the hypothesis explaining the order of the stabilities on the basis of the ionic radii. It cannot be argued that stability increases until copper, and then decreases solely on the basis that it is also the order of decreasing ionic radius, being smallest for $\mathrm{Cu}^{2+}$. Only Refs 18 and 19 give the smallest value for the cupric ion. Since the differences are quite significant we did not attempt to plot either the radius or its reciprocal against other properties. It is however surptising that, despite the differences in the $r$ values, the second ionization potentials of the elements have constant values in the reported literature. The agreed values are ${ }^{(23)}$ :

$$
\begin{array}{llllll}
\text { Ions } & \mathrm{Fe}^{2+} & \mathrm{Co}^{2+} & \mathrm{Ni}^{2+} & \mathrm{Cu}^{2+} & \mathrm{Zn}^{2+} \\
\text { 2nd i.p. (eV) } & 16.18 & 17.06 & 18.17 & 20.29 & 17.96
\end{array}
$$

A plot of second ionization potential versus the atomic number $(Z)$ of the elements is shown in Figure 5. This clearly establishes a regular increase from $\mathrm{Fe}^{2+}$ to $\mathrm{Cu}^{2+}$ followed by a decrease for $\mathrm{Zn}^{2+}$.

The results of the cobalt(II), nickel(II) and copper(II) chloro complexes in methanol, ethanol and propan-2-ol are summarized in Table 1. A plot of logarithm of the stability constants of the first complex versus $Z$ is presented in Figure 6 . This graph, besides showing higher stability in the higher alcohol, shows that, for all three alcohols, the stability of the chloro complexes increases slightly from cobalt to nickel and then there is a marked increase from

Table 1. Logarithms of the overall stability constants $\log \beta_{j}$ of the chloro complexes of $\mathrm{Co}^{\mathrm{II}}, \mathrm{Ni}^{\mathrm{II}}$, and $\mathrm{Cu}^{\mathrm{II}}$ in $\mathrm{MeOH}, \mathrm{EtOH}$ and $\mathrm{PrOH}$

\begin{tabular}{lllllllllllll}
\hline Solvent & $\begin{array}{l}\mathrm{Co} \\
\log \beta_{1}\end{array}$ & $\log \beta_{2}$ & $\log \beta_{3}$ & Ref. & $\log \beta_{1}$ & $\log \beta_{2}$ & Ref. & $\begin{array}{c}\mathrm{Cu} \\
\log \beta_{1}\end{array}$ & $\log \beta_{2}$ & $\log \beta_{3}$ & $\log \beta_{4}$ & Ref. \\
\hline $\mathrm{MeOH}$ & 1.2 & 1.7 & 1.4 & $\mathrm{a}$ & 1.3 & 1.2 & 14 & 2.5 & 4.2 & 5.4 & 5.7 & 15 \\
$\mathrm{EtOH}$ & 1.3 & 2.8 & 4.1 & 1 & 1.7 & 1.8 & 14 & 3.3 & 6.0 & 7.8 & 8.3 & 16 \\
$\mathrm{PrOH}$ & 1.7 & 3.3 & 4.7 & 1 & 1.9 & 2.2 & 14 & 4.0 & 7.0 & 8.6 & 9.6 & 17 \\
\hline
\end{tabular}

\footnotetext{
a This work.
} 
Table 2. Ionic radii $(\AA)$ of the divalent cations of some metals of the first transition series

\begin{tabular}{lllllll}
\hline $\begin{array}{lllll}\text { Ions } \\
Z\end{array}$ & $\begin{array}{l}\mathrm{Fe}^{2+} \\
26\end{array}$ & $\begin{array}{l}\mathrm{Co}^{2+} \\
27\end{array}$ & $\begin{array}{l}\mathrm{Ni}^{2+} \\
28\end{array}$ & $\begin{array}{l}\mathrm{Cu}^{2+} \\
29\end{array}$ & $\begin{array}{l}\mathrm{Zn}^{2+} \\
30\end{array}$ & $\mathrm{Ref}$. \\
\hline Radii $(\AA)$ & 0.76 & 0.78 & 0.78 & 0.69 & 0.74 & 19 \\
& 0.75 & 0.72 & 0.69 & & & 20 \\
& 0.77 & 0.72 & 0.69 & 0.71 & 0.74 & 21 \\
& 0.78 & 0.75 & 0.69 & 0.73 & & 22 \\
& 0.74 & 0.72 & 0.69 & 0.72 & 0.74 & 23 \\
& 0.76 & 0.74 & 0.73 & 0.72 & 0.72 & 18 \\
& 0.63 & & & 0.73 & 0.75 & 24 \\
& 0.78 & 0.82 & 0.69 & 0.70 & 0.74 & 25 \\
\hline
\end{tabular}

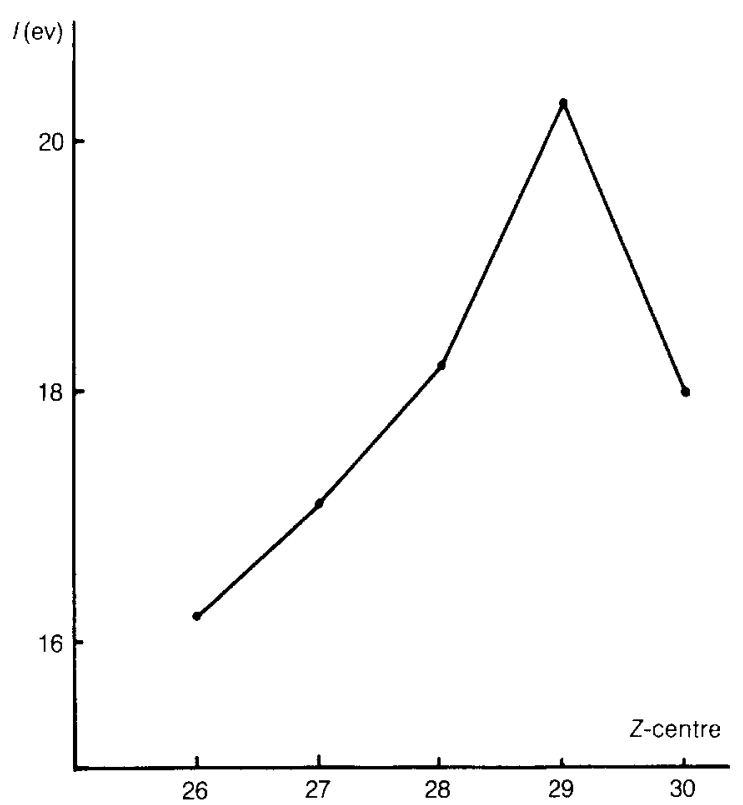

Figure 5. Second ionization potentials of the elements in function of their atomic numbers.

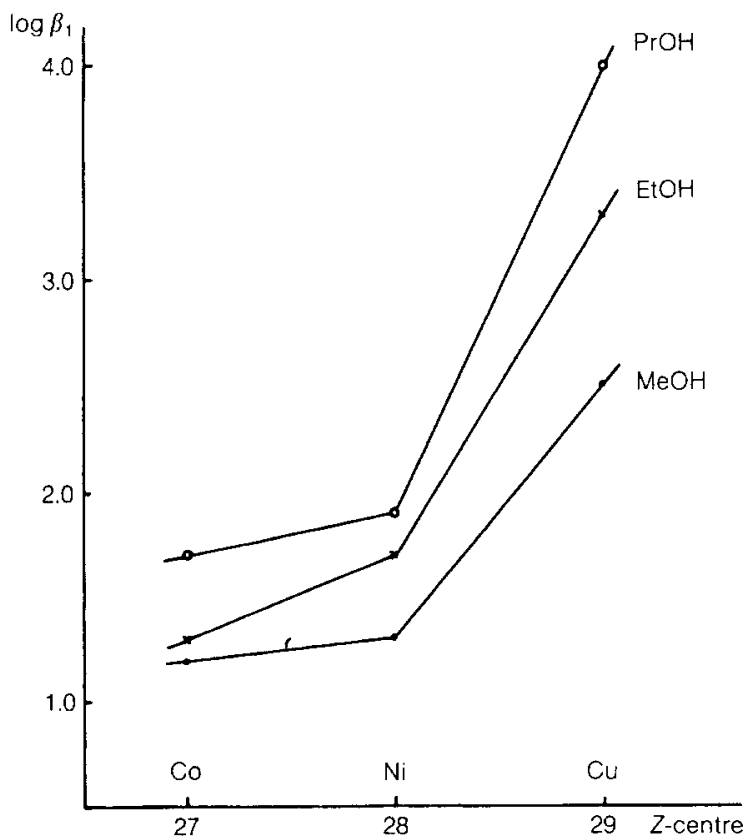

Figure 6. Variations of $\log \beta_{1}$ with respect to the atomic number of the central metal ions. nickel to copper. One can easily predict, by comparing Figures 5 and 6, that the formation constants of zinc(II) chloro complexes will be lower than those of copper.

\section{Conclusion}

The stability of the first transition metal complexes in aqueous as well as in organic media is in accordance with the Irving-Williams series. The order of stability as given by these authors closely parallels our results with the chloride ions as ligands and in the alcoholic medium. Other explanations of the Irving-Williams order of stabilities are found in the literature based on crystal field theory, which takes into account the crystal field stabilization energy. A parsimonious explanation for this order is simply the increasing second ionization potentials until copper, a fact which facilitates ready substitution of solvent molecules by successive ligand groups.

\section{References}

(1) S. Lechat, M. A. Khan, G. Bouet and F. Vierling, Inorg. Chim. Acta, 211, 33 (1993).

${ }^{(2)}$ L. I. Katzin and E. Gebert, J. Amer. Chem. Soc., 72, 5464 (1950).

(3) D. A. Fine, J. Amer. Chem. Soc., 84, 1140 (1962).

${ }^{(4)}$ F. A. Cotton, D. M. L. Goodgame and M. Goodgame, $J$. Amer. Chem. Soc., 83, 4690 (1961)

${ }^{(5)}$ E. Wendling, O. Benali-Bailich and G. Yaker, Rev. Chim. Miner., 8, 559 (1971).

${ }^{(6)}$ A. H. Zeltman, N. A. Tiatwiyoff and L. O. Morgan, J. Phys. Chem., 72, 121 (1968).

(7) J. Bjerrum, A. S. Halonin and L. H. Skibsted, Acta Chem. Scand., Ser. A, 32, 429 (1978).

${ }^{(8)}$ A. Chiboub Fellah, Doctoral Thesis, Université Louis Pasteur, Strasbourg, January (1991).

${ }^{(9)}$ Z. Z. Hugus and A. A. El Awady, J. Phys. Chem., 75(19), 2954 (1971).

${ }^{(10)}$ F. Vierling, M. J. Schwing and J. Meullemeestre, Spectra 2000, 79(10), 25 (1982).

(11) J. Byé, R. Hugel, G. Schorsch and R. Strosser, Bull. Soc. Chim. Fr., 1146 (1964)

(12) D. W. Marquardt, J. Soc. Ind. Appl. Math., 11(2), 431 (1963).

${ }^{(13)}$ E. Bentouhami, M. A. Khan, J. Meullemeestre and F. Vierling, Polyhedron., 11(17), 2179 (1992)

${ }^{(14)}$ M. A. Khan, D. Cronier, G. Bouet and F. Vierling, Transition Met. Chem., 20, 369 (1995).

${ }^{(15)}$ M. A. Khan, J. Meullemeestre, M. J. Schwing and F. Vierling, Inorg. Chem., 28, 3306 (1989).

${ }^{(16)}$ S. Chafaa, T. Douadi, M. A. Khan, J. Meullemeestre, M. J. Schwing and F. Vierling, Nouv. J. Chim., 15, 39 (1991)

${ }^{(17)}$ F. Djabi, J. Meullemeestre, F. Vierling, G. Bouet and M. A. Khan, Bull. Soc. Chim. Fr., 131, 53 (1994).

${ }^{(18)}$ H. Irving and R. J. P. Williams, J. Chem. Soc., 3192 (1953).

${ }_{19)}$ R. B. Heslop and P. L. Robinson, Chimie Inorganique, Flammarion Sciences, Paris, 1973, p. 597.

${ }^{(20)}$ H. J. Emeleus and J. S. Anderson, Modern Aspects of Inorganic Chemistry, 3rd Edition, ELBS, London, 1962, p. 86.

${ }^{(21)}$ F. A. Cotton and G. Wilkinson, Advanced Inorganic Chemistry, 5th Edit., Wiley, New York, 1988, Appendix 4, ionic radii, p. 1388.

${ }^{(22)}$ A. F. Wells, Structural Inorganic Chemistry, 5th Edit. Clarendon Press, Oxford, 1987, p. 313.

${ }^{(23)}$ Handbook of Chemistry and Physics, 69 th Edit. CRC Press, Boca Raton, 1988-89, pp. E-78, and F-164.

${ }^{(24)}$ P. W. Atkins, Physical Chemistry, 4th Edit., Oxford University Press, Oxford, 1990, p. 959.

${ }^{(25)}$ H. B. Gray and G. P. Haight, Principes de Chimie, Ediscience, Paris, 1973, p. 69.

(Received 10 October 1995

Accepted 24 November 1995)

TMC 3597 